COMUNICAÇÃOCIENTÍFICA

\title{
CARACTERIZAÇÃO DE GENES DIFERENCIALMENTE EXPRESSOS NA INTERAÇÃO ENTRE MAÇÃ 'FUJI' e Botryosphaeria dothidea ${ }^{1}$
}

\author{
ADRIANA REGINA CORRENT² ${ }^{2}$ LIGIALOSS SCHWARZ $^{3}$, ANDRÉIA HANSEN OSTER $^{4}$, \\ MARCELO GRAVINADEMORAES ${ }^{5}$, RENAR JOÃO BENDER ${ }^{5}$
}

RESUMO - O objetivo deste estudo foi investigar a interação entre o fungo Botryosphaeria dothidea e maçãs cv. Fuji por meio da técnica de Differential Display RT-PCR. O cDNA de frutos infectados e não infectados pelo fungo foi amplificado com uma combinação de 15 oligonucleotídeos iniciadores. Foram isolados 400 fragmentos de cDNA diferencialmente expressos, dos quais 120 foram sequenciados e comparados com sequências disponíveis no GenBank, por meio do programa BLASTX. As sequências obtidas foram similares à metalotioninas, profilina alergênica, proteína de resistência e fosfatase.

Termos para indexação: Malus domestica, podridão-branca, transcriptase reversa.

\section{CHARACTERIZATION OF DIFFERENTLY EXPRESSED GENES DURING THE INTERACTION BETWEEN 'FUJI'APPLES AND Botryosphaeria dothidea}

\begin{abstract}
The aim of this study was to investigate the interaction between the Botryosphaeria dothidea fungi and 'Fuji' apples using the Differential Display RT-PCR technique. The cDNA of infected and non infected fruits by the fungus was amplified using a combination of 15 primers. Four hundred fragments of differentially expressed cDNA were isolated, and 120 of them were sequenced and compared with available sequences at GenBank database, using BLASTX software. Obtained sequences were similar to methalothionines, an allergenic profiline, a resistance linked protein, and a phosphatase.
\end{abstract}

Index terms: Malus domestica, white-rot, reverse transcriptase.

Consideradas um problema da cultura da macieira (Malus domestica (Borkh), as podridões em pós-colheita são responsáveis por até $35 \%$ das perdas de frutos quando submetidos a manejo inadequado durante o período de armazenamento. Os fungos são os principais agentes causadores de podridões em maçãs nesta fase. Entre eles, destacase Botryosphaeria dothidea (Moug.:Fr.), causador da podridão-branca em maçãs. Sabe-se que este fungo pode infectar os frutos no início do ciclo vegetativo, permanecer latente até o início da maturação e desenvolver-se também sob refrigeração (Boneti et al., 1999).

As interações planta-patógeno são caracterizadas por mudanças na expressão gênica de ambos os organismos (Benito et al., 1996). A identificação de genes envolvidos nas respostas de defesa, nos hospedeiros, é importante para a elucidação dos mecanismos de defesa da planta contra os fitopatógenos. A seleção diferencial de bibliotecas de DNA complementar ao mRNA (cDNA), produzidas a partir de mRNAs isolados de plantas infectadas com patógenos, tratadas com elicitores ou indutores de resistência, é utilizada para identificar genes relacionados à defesa em muitas interações planta-patógeno (Sanches-Torres \& GonzalezCandelas, 2003).

Dentre as metodologias usadas para a identificação e isolamento de genes expressos diferencialmente, o 'Differential Display Transcriptase Reversa PCR (DD-RT-PCR) (Liang \& Pardee, 1992) é um método baseado em PCR (Reação em Cadeia da Polimerase) que permite a análise da expressão gênica durante as interações patógenohospedeiro, permitindo a identificação de genes diferencialmente expressos durante o processo de

\footnotetext{
'(Trabalho 076-08). Recebido em: 27-03-2008. Aceito para publicação em: 20-11-2008.

${ }^{2}$ Eng. Agr. Dra. Professora do CEFET - Januária-MG. E-mail: acorrent@gmail.com

${ }^{3}$ Graduanda Faculdade de Agronomia, UFRGS. E-mail: ligiloss@yahoo.com

${ }^{4}$ Eng. Agr. Dra. Pesquisadora Embrapa Agroindústria Tropical. E-mail: andreia@cnpat.embrapa.br

${ }^{5}$ Eng. Agr. Dr. Professor Faculdade de Agronomia, UFRGS. E-mail: mgm@ufrgs.br; rjbe@ufrgs.br
} 
infecção (Benito et al., 1996).

Este trabalho teve por objetivo identificar genes envolvidos na interação $B$. dothidea e maçãs da cv. Fuji, por meio da técnica de DD-RT-PCR.

$\mathrm{O}$ inóculo de $B$. dothidea foi obtido a partir de maçãs da cv. Fuji com sintomas típicos de podridão-branca. Os isolados foram cultivados em placas de Petri contendo meio de cultura batatadextrose-ágar (BDA- 20 g.L. $\mathrm{L}^{-1}$ de ágar, 20 g.L $\mathrm{L}^{-1}$ de dextrose e caldo de 200 g. $\mathrm{L}^{-1}$ de batata) e mantidos em câmara de crescimento a $26^{\circ} \mathrm{C}$ sob luz contínua, (lâmpada fluorescente) durante sete dias.

As maçãs 'Fuji' utilizadas neste experimento foram provenientes da empresa Mercochem de Caxias do Sul-RS. Na inoculação, uma suspensão de $10^{6}$ conídios $\mathrm{mL}^{-1}$ do fungo foi inoculada aos frutos, e, posteriormente, as maçãs foram mantidas em câmara de crescimento a $26^{\circ} \mathrm{C}$. Amostras de tecido de maçãs inoculadas e não inoculadas foram coletadas no período de $3 ; 12 ; 48$ e 72 h após a inoculação e armazenadas a $-80^{\circ} \mathrm{C}$.

Os tratamentos foram: T1 - frutos não inoculados; T2 - 3h após a inoculação; T3 -12 h após a inoculação; T4 - 48 h após a inoculação; T5 $72 \mathrm{~h}$ após a inoculação. O RNA total foi extraído a partir de $400 \mathrm{mg}$ de tecido dos frutos, utilizando o kit Concert Plant RNA Reagent (Invitrogen, Carlsbad, USA). O RNA total (1 a $2 \mu \mathrm{g}$ ) foi transcrito reversamente (RT), adicionando $1,32 \mu \mathrm{M}$ de cada um dos oligonucleotídeos iniciadores (âncora) (Tabela 1), 0,4 mM de cada desoxirribonucleotídeo tri-fosfato (dNTP) (Invitrogen, Carlsbad, USA); 50 mM de Tris$\mathrm{HCl}(\mathrm{pH} \mathrm{8,3);} 75 \mathrm{mM}$ de $\mathrm{KCl} ; 6,6 \mathrm{mM}$ de ditiotreitol (DTT); $200 \mathrm{U}$ da enzima transcriptase reversa (MMLVRT) (Amershan Biosciences, Piscataway, USA) e água ultrapura, até completar o volume de $5 \mu \mathrm{L}$. A reação foi incubada no termociclador PTC-100 (MJ Research), por uma hora, à temperatura de $37^{\circ} \mathrm{C}$.

A PCR foi composta de $5 \mu \mathrm{L}$ do cDNA; 20 $\mathrm{mM}$ de Tris- $\mathrm{HCl}(\mathrm{pH} \mathrm{8,3);} 50 \mathrm{mM}$ de $\mathrm{KCl} ; 2 \mathrm{mM}$ de $\mathrm{MgCl}_{2} ; 0,2 \mathrm{mM}$ de cada dNTP; (Invitrogen, Carlsbad, USA); $0,8 \mu \mathrm{M}$ de cada um dos oligonucleotídeos âncora; 0,8 $\mu \mathrm{M}$ de cada um dos nucleotídeos arbitrários, (Sanches-Torres \& Gonzalez-Candelas, 2003) (Tabela 01); 3U da enzima Taq DNA Polimerase (Invitrogen, Carlsbad, USA) para um volume final de $50 \mu \mathrm{L}$. Foram testadas 15 combinações de oligonucleotídeos. A reação foi incubada no termociclador PTC-100 (MJ Research) nas seguintes condições: desnaturação inicial a $95^{\circ} \mathrm{C}$, por $2 \mathrm{~min}, 17$ ciclos constituídos de desnaturação a $95^{\circ} \mathrm{C}$, por 30 $\mathrm{s}$, anelamento a $50^{\circ} \mathrm{C}$, por 2 min, extensão a $72^{\circ} \mathrm{C}$, por 90 s e extensão final a $72^{\circ} \mathrm{C}$, por $5 \mathrm{~min}$, num total de 39 ciclos. Os produtos da PCR foram submetidos à eletroforese em gel de poliacrilamida desnaturante $6 \%(0,8 \%$ de acrilamida; $19,46 \mathrm{mM}$ de N,Nmetabisalacrilamida; $7 \mathrm{M}$ de uréia; $90 \mathrm{mM}$ de ácido bórico; $2 \mathrm{mM}$ de EDTA; 4,4 $\mathrm{mM}$ de persulfato de amônio; 3,9 mM de N,N,N,N-tetrametiletilenodiamino, TEMED). A eletroforese foi realizada utilizando-se do sistema de sequenciamento Hoefer SQ3 (Amershan Biosciences, Piscataway, USA).

Os fragmentos de interesse foram isolados do gel conforme método proposto por Song et al. (1995). Em seguida, foram coletados, eluídos e submetidos a uma reamplificação por PCR com os mesmos iniciadores e as mesmas condições da amplificação. Os produtos da reamplificação foram resolvidos em gel de agarose $2 \%$ e fotodocumentados com o sistema Kodak Digital Science 1D-EDAS 120. Após a reação de reamplificação, as amostras foram quantificadas em espectrofotômetro e então submetidas à purificação com as enzimas ExoSAP-IT (USB, Cleveland, USA), pela incubação a $37^{\circ} \mathrm{C}$, por $15 \mathrm{~min}$, seguido de $80^{\circ} \mathrm{C}$, por $15 \mathrm{~min}$.

Os fragmentos foram sequenciados, utilizando-se do sistema "DYEnamic ET Dye Terminator Cycle Sequencing kit for MegaBACE DNA Analysis Systems" no sequenciador automático MegaBACE (Amershan Biosciences, Piscataway, USA), com uso de $100 \mathrm{ng}$ do produto de PCR e 0,25 $\mu \mathrm{M}$ do oligonucleotídeo iniciador E-0, de acordo com as instruções do fabricante. As sequências obtidas foram comparadas com sequências depositadas no National Center for Biotecnology Information - NCBI (GenBank), utilizando-se do algoritmo BLASTX, (Basic Local Alignment Search Toll- http://blast.ncbi.nlm.nih.gov/ Blast)(Altschul et al.,1990).

Com a utilização de 15 combinações de oligonucleotídeos iniciadores, foi possível identificar 400 fragmentos de cDNAs, correspondentes a genes diferencialmente expressos, ou seja, que tiveram sua expressão aumentada ou reprimida quando comparados os cinco tratamentos lado a lado. Foram purificados 120 fragmentos de cDNAs, sequenciados e as sequências obtidas foram comparadas com as disponíveis no GenBank. Destas 120 sequências, 30 não apresentaram similaridade com nenhuma outra depositada no banco e 14 apresentaram similaridade com metalotioninas do tipo II (Mets) de M. domestica. Duas outras sequências foram similares a proteínas de $M$. domestica: uma proteína de resistência contendo o domínio CC-NBS-LRR (sítio de ligação a nucleotídeo, repetições ricas em leucina e coiled coil) e uma profilina alergênica. Também foi encontrada 
similaridade com uma proteína fosfatase induzida por ácido abscísico e cálcio de Fagus sylvatica e duas proteínas hipotéticas SHOOT2 (Glycine max), conforme apresentado na Tabela 2.

Metalotioninas (Mets) são polipeptídios ricos em resíduos de cisteínas e estão envolvidos na detoxificação de metais e na homeostase em procariotos e eucariotos. Esses resíduos de cisteína ligam-se a metais como cobre, zinco e cádmio (Hamer et al., 1985). Neste trabalho, foram observados clones com alta similaridade a Mets do tipo II de $M$. domestica tanto na testemunnha como nos frutos inoculados. Reid \& Ross (1997) encontraram esse tipo de Mets em frutos de maçã em resposta ao armazenamento refrigerado. Os frutos utilizados neste experimento foram previamente submetidos ao armazenamento em câmaras frias, como forma habitual de conservação e redução do processo de maturação. Estes genes podem ter sido expressos como resposta às condições de frio durante o armazenamento.

Recentemente, Degenhardt et al. (2005) encontraram um grande número de clones de Mets do tipo III em M. domestica. O aumento da expressão dos transcritos de Mets ocorreu após a infecção com o fungo $V$. inaequalis, na cultivar Elstar, suscetível a sarna. De acordo com esses autores, a expressão constitutiva dessas Mets na cultivar resistente pode ser fator de proteção a diferentes patógenos. A função exata das Mets durante a interação com patógenos não está bem clara, mas presume-se estar envolvida na proteção de tecidos atacados, com a função de minimizar os danos ocasionados pelo excesso de espécies reativas de oxigênio no local da infecção (Alscher et al., 2002).

Um fragmento similar a uma proteína de resistência contendo os domínios NBS-LRR-CC de M. domestica, foi isolado em T4. A classe de proteínas NBS-LRR-CC é bastante estudada, uma vez que estas são codificadas por um grande número de genes em plantas (McHale et al., 2006). Proteínas contendo domínios NBS-LRR estão envolvidas em uma série de mecanismos de defesa nas plantas, como a ativação da explosão oxidativa, o fluxo de íons de cálcio e as cascatas de proteínas quinases associadas à indução de genes relacionados à patogênese e repostas de hipersensibilidade (Van der Biezen \& Jones, 1998; Peyyala \& Farman, 2006). Essas proteínas conferem resistência a uma ampla gama de patógenos, incluindo bactérias, fungos, viroses e nematóides (Wang et al., 1999).

Em frutos submetidos à inoculação, observou-se uma sequência de aminoácidos similar à proteína fosfatase $2 \mathrm{C}(\mathrm{PP} 2 \mathrm{C})$ de Fagus sylvatica, que pertence a uma classe de proteínas conservadas, ricas em serina e treonina, envolvidas em resposta a estresses (Vranova et al., 2000), e que atuam como reguladores negativos em diferentes rotas de sinalização, como a da resposta a ferimentos, mediada por ácido abscísico (ABA) (Carrera \& Prat, 1998). Inúmeras fosfatases pertencentes a essa mesma classe (PP2C) foram encontradas em maçãs submetidas à inoculação por Penicillium expansum no trabalho desenvolvido por Sanches-Torres \& Gonzalez-Candelas (2003). Esses autores observaram a presença de elevados níveis de expressão dessa proteína somente em frutos inoculados, o que representaria uma resposta específica dos frutos ao patógeno. Contudo, de acordo com os autores, a função desta enzima durante a interação plantapatógeno ainda não é conhecida.

Um fragmento isolado em T5 mostrou similaridade com o gene Mal d4 de $M$. domestica. Esse gene é responsável pela codificação de proteínas alergênicas em maçãs, denominadas profilinas. As profilinas são proteínas pequenas (12$16 \mathrm{kd}$ ), presentes nos organismos eucarióticos, cujas funções são regular: alterações na estrutura do citoesqueleto e ligar-se à actina (G-actina), na razão de 1:1, e à polimerização da actina em filamentos (Witke, 2004).

Maçãs possuem quatro classes de proteínas alergênicas, sendo denominadas Mal d1, Mal d2, Mal d3 e Mal d4, sendo que Mal d1 é uma PR10 (Gao et al., 2005). A Mal d2 é uma proteína do tipo taumatina que pertence à classe das PR5 e está envolvida nas respostas de defesas das plantas contra patógenos de origem fúngica. Esta atividade já foi comprovada sobre os fungos patogênicos Fusarium oxysporum e Penicillium expansum (Beuning et al., 2004). Até o momento, não existe nenhum trabalho relacionando estas profilinas a respostas de defesa em frutos de maçã, mas outras profilinas conhecidas como a Bet v1 (Betula alleghaniensis) atuam nas respostas de defesa a patógenos (Beuning et., 2004). Ambas Bet v1 e Mal d1 são classificadas como pertencentes à classe das PR10, devido a sua homologia com estas proteínas (Liu \& Ekramoddoullah, 2004). Trabalhos adicionais são necessários para verificar a expressão das profilinas de maçã em resposta a patógenos.

A técnica de DD-RT-PC permitiu o isolamento de genes diferencialmente expressos durante a interação de maçãs com $B$. dothidea. Das quatro proteínas diferencialmente expressas, três, presentes em frutos infectados, estão relacionadas com funções de respostas de defesa a estresses. 
TABELA 1 - Sequência de oligonucleotídeos iniciadores baseados no trabalho de Sanches-Torres \& GonzalezCandelas (2003).

\begin{tabular}{cc}
\hline Oligonucleotídeos Iniciadores & \multicolumn{1}{c}{ Sequência 5'-3' } \\
\hline Ancoras & \\
\hline AP31 & TTC GGA TCC CCA TTT TTT TTT TTA \\
AP32 & TTC GGA TCC CCA TTT TTT TTT TTC \\
AP33 & TTC GGA TCC CCA TTT TTT TTT TTG \\
\hline Arbitrários & \\
\hline AP51 & TCT GAA TTC CCT CAA CGA GG \\
AP52 & TCT GAA TTC CCT CAT TGG TC \\
AP53 & TCT GAA TTC CCT CAC CAA TC \\
AP54 & TCT GAA TTC CCT CAT ACA GG \\
AP55 & TCT GAA TTC CCT CGT CAT AG \\
\hline
\end{tabular}

TABELA 2 - Análise da similaridade de sequências isoladas através da técnica de DD-RT-PCR na interação entre $B$. dothidea e maçãs, através do programa BlastX.

\begin{tabular}{lcclc}
\hline Trat amento & Acesso & Tam (pb) & \multicolumn{1}{c}{ Acesso } & Valor de E \\
\hline $\mathbf{1 , 3}, \mathbf{4}$ e 5 & U61973 & 511 & Metalotionina AMT1 (M. domestica) & $1 \times 10^{-50}$ \\
$\mathbf{2}$ & AJ277744 & 807 & Proteína fosfatase 2C (PP2C) (Fagus sylvatica) & $3 \times 10^{-25}$ \\
$\mathbf{2}$ e 5 & AJ507459 & 355 & Profilina alergênica (M. domestica) & $5 \times 10^{-43}$ \\
$\mathbf{4}$ & AM167520 & 306 & PR CC-NBS-LRR (M. domestica) & $3 \times 10^{-75}$ \\
$\mathbf{1}$ & AF350328 & 255 & Proteína hipotética SHOOT2 (G. max) & $7 \times 10^{-17}$ \\
\hline
\end{tabular}

\section{REFERÊNCIAS}

ALSCHER, R. G.; ERTURK, N.; HEATH, S.L. Role of superoxide dismutases (SODs) in controlling oxidative stress in plants. Journal of Experimental Botany, Oxford, v. 53, n. 372, 1331-1341, 2002.

BENITO, E.P.; PRINS, T.; VAN KAN, J.A.L. Application of differential display RT-PCR to the analysis of gene expression in a plant-fungus interaction. Plant Molecular Biology, Dordrecht, v.32, p.937-947, 1996.

BEUNING, L.; BOWEN, J.; PERSSON, H. et al. Characterisation of Mal d 1-related genes in Malus. Plant Molecular Biology, Dordrecht, v.55, p.369-388, 2004.

BONETI, J.I.S.; RIBEIRO, L.G.; KATSURAYAMA, Y. Manual de identificação de doenças e pragas da macieira. Florianópolis: Epagri, 1999. 149 p.

CARRERA, E.; PRAT, S. Expression of the Arabidopsis abi1-1 mutant allele inhibits proteinase inhibitor wound-induction in tomato. Plant Journal, Oxford, v.15, p.765-771, 1998.

DEGENHARDT, J.; MASRI, A. N.; RKCU, S. K. et al. Characterization by suppression subtractive hybridization of transcripts that are differentially expressed in leaves of apple scab-resistant and susceptible cultivars of Malus domestica. Molecular Genetics and Genomics, Berlin, v.273, p.326-335, 2005.

GAO, Z.S.; VAN DE WEG, W.E.; SCHAART, J.G. et al. Linkage map positions and allelic diversity of two Mal d 3 (non-specific lipid transfer protein) genes in the cultivated apple (Malus domestica). Theoretical and Applied Genetics, Berlin, v.110, n.3, p. 479-491, 2005.

HAMER, D.H.; THIELE, D.,J.; LEMONTT, J.E. Function and autoregulation of yeast copperthionein. Science, Washington, v.228, p.685690, 1985.

LIANG, P.; PARDEE, A.B. Differential display of eukaryotic messenger RNA by means of the polymerase chain reaction. Science, Washington, v. 257, p. 967-971, 1992.

LIU, J.J.; EKRAMODDOULLAH, A.K.M. Isolation, genetic variation and expression of TIR-NBS-LRR resistance gene analogs from western white pine (Pinus monticola Dougl. ex. D. Don.). Molecular Genetics and Genomics, Berlin, v. 270, n. 5, 2004. 
MCHALE, L.; TAN, X.; KOEHL, P. MICHELMORE, R.W. Plant NBS-LRR proteins: adaptable guards. Genome Biology, London, v.7, p.212- 2006.

PEYYALA, R.; FARMAN, M. L. Magnaporthe oryzae isolates causing gray leaf spot of perennial ryegrass possess a functional copy of the AVR1-CO39 avirulence gene. Plant Molecular Pathology, Dordrecht, v.7, p.157-165, 2006.

REID, S.; ROSS, G.S. Up-regulation encoding metallothionein-like proteins storage. Physiologia Plantarum, Edinburger, v.100, p.183-189, 1997.

SÁNCHEZ-TORRES, P.; GONZÁLEZ-CANDELAS, L. Isolation and characterization of genes differentially expressed during the interaction between apple fruit and Penicillium expansum. Plant Molecular Pathology,Dordrecht, v.4, p.447-457, 2003.

SONG, W.Y.; WANG, G.L.; CHEN, L.L. et al. A receptor kinase-like protein encoded by the rice disease resistance gene, Xa21. Science, Washington, v.270, p.1804-6, 1995.
VAN DER BIEZEN, E. A.; JONES, J.G.D. The NBARC domais: A novel signaling motif shared by plant resistance gene products and regulators of cell death in animals. Current Biology, London, v. 8, n.7, p. R226-R228, 1998.

VRANOVA, E.; LANGEBARTELS, C.; VAN MONTAGU, M. et al. Oxidative stress, heat shock and drought differentially affect expression of a tobacco protein phosphatase 2C. Journal of Experimental Botany, Oxford, v.51, p.1763-4, 2000.

WANG, Z.X.; YANO, M.; YAMANOUCHI, U. et al. The $P i b$ gene for rice blast resistance belongs to the nucleotide binding and leucine-rich repeat class of plant disease resistance genes. Plant Journal, Oxford, v. 19:55-64, 1999.

WITKE, W. The role of profilin complexes in cell motility and other cellular processes. Trends in Cell Biology, Cambridge, v.14, p.461-9, 2004. 